\title{
Article
}

\section{Health promoting universities: effective leadership for health, well-being and sustainability}

Dooris, Mark T, Powell, Susan, Parkin, Doug and Farrier, Alan Available at http://clok.uclan.ac.uk/36934/

Dooris, Mark T ORCID: 0000-0002-5986-1660, Powell, Susan, Parkin, Doug and Farrier, Alan ORCID: 0000-0003-4989-2209 (2021) Health promoting universities: effective leadership for health, well-being and sustainability. Health Education, 121 (3). pp. 295-310. ISSN 0965-4283

It is advisable to refer to the publisher's version if you intend to cite from the work. http://dx.doi.org/10.1108/HE-12-2020-0121

For more information about UCLan's research in this area go to http://www.uclan.ac.uk/researchgroups/ and search for < name of research Group>.

For information about Research generally at UCLan please go to http://www.uclan.ac.uk/research/

All outputs in CLoK are protected by Intellectual Property Rights law, including Copyright law. Copyright, IPR and Moral Rights for the works on this site are retained by the individual authors and/or other copyright owners. Terms and conditions for use of this material are defined in the policies page.

\section{CLoK}

Central Lancashire online Knowledge www.clok.uclan.ac.uk

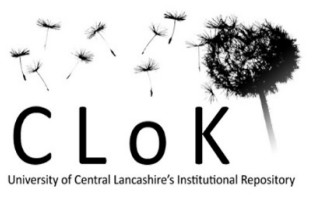




\title{
Health Promoting Universities: Effective Leadership for Health, Wellbeing and Sustainability
}

\author{
AUTHORS \\ Mark Dooris, University of Central Lancashire \\ Susan Powell, Manchester Metropolitan University \\ Doug Parkin, Advance-HE \\ Alan Farrier, University of Central Lancashire
}

\begin{abstract}
Design/methodology/approach - A multi-method qualitative approach was used: semi-structured interviews and focus groups were conducted with vice-chancellors $(n=12)$ and UK Healthy Universities Network members $(n=10)$; online questionnaires were completed by non-UK network co-ordinators $(n=6)$ and non-UK Health Promoting University co-ordinators $(n=10)$, supplemented with two interviews.
\end{abstract}

Purpose - This paper reports on a research study examining opportunities for and characteristics of effective leadership for whole university approaches to health, wellbeing and sustainability.

Findings - Two overarching themes emerged: opportunities to secure and sustain effective seniorlevel leadership; and characteristics of effective senior-level leadership. Sub-themes under 'Opportunities' included: aligning work with core business so that health and wellbeing becomes a strategic priority; harnessing the personal qualities and values of senior-level advocates; and using charters and policy drivers as levers to engage and catalyse action. Sub-themes under 'Characteristics' included: commitment to whole university/whole system working; an understanding that health underpins core business and is a strategic priority; enabling effective coordination through appropriate resourcing; balancing top-down and distributed leadership models; and complementing strategic leadership with cultural change.

Originality/value - This study is one of the first to explore leadership in relation to Health Promoting Universities. Drawing on the findings, it presents a guide to developing and securing effective leadership for Health Promoting Universities - of value to researchers, practitioners and policy-makers worldwide.

\section{Key Words}

Healthy Universities; Health Promoting Universities; Leadership; Whole System; Qualitative Evaluation 
Pre-Print Version, accepted for publication in Health Education;

https://www.emerald.com/insight/content/doi/10.1108/HE-12-2020-0121/full/html

[subject to proofing]

\section{Introduction}

This paper reports on an international research study examining opportunities for and characteristics of effective leadership for whole university approaches to health, wellbeing and sustainability. It is widely appreciated that student and staff health and wellbeing impact on the core business of higher education institutions (HEIs) and are fundamental to successful performance and productivity (Dooris et al., 2020; Universities UK, 2016a). There is also growing appreciation that human and planetary health are interconnected (World Health Organization, 2016) and that universities are important 'place-shapers' - through civic and wider societal engagement (Goddard, 2009; UPP Foundation, 2019). These discourses suggest that there is significant 'added value' in connecting health, wellbeing and sustainability agendas (Orme and Dooris, 2010).

Higher education [1] is one key sector in which the healthy settings approach has been applied. Widely understood to have originated through the Ottawa Charter for Health Promotion, this approach is based on understanding that "health is created and lived by people within the settings of their everyday life; where they learn, work, play and love" (World Health Organization, 1986:2). A conceptual framework for healthy settings has been proposed (Dooris, 2013, 2014), highlighting key characteristics: a salutogenic view concerned not only with illness, but with wellbeing and what makes people flourish; an ecological model, appreciating that human health is determined by a complex interaction of personal, social, behavioural and environmental factors; a systems perspective, acknowledging interconnectedness and synergy between components within and between settings; a comprehensive holistic change focus, using multiple, interconnected interventions to embed health; and an appreciation that most settings - including universities - do not have health as their main mission, making it essential to advocate for health in terms of impact on or outflow from core business.

As a movement, Health Promoting Universities [2] first developed in the United Kingdom during the mid-1990s, catalysing activity at European and global levels (Suarez-Reyes and Van den Broucke, 2016). Since then, an increasing number of national and trans-national networks have been established, seeking to implement a whole university/whole system approach to health, wellbeing and sustainability. Such an approach prioritises: creating and sustaining a supportive culture and environment; embedding and joining up health; and focusing on the whole population (Dooris et al., 2020). This emerging global movement has, over the past few years, coalesced, guided by the vision and objectives of the Okanagan Charter for Health Promoting Universities and Colleges (2015), a major outcome of an international conference attended by 375 participants from 32 countries. This contends that "health promoting universities and colleges transform the health and sustainability of our current and future societies, strengthen communities and contribute to the wellbeing of people, places and the planet" (2015:2) and calls upon higher education institutions (HEls) to incorporate health and sustainability into their mission, vision and strategic plans; and lead and drive change in society by modelling, testing and transferring innovative approaches.

Key to developing and sustaining Health Promoting Universities, effective leadership embraces multiple important facets. Firstly, it must be context-sensitive (Parkin, 2017). The context of higher education is rich, complex and diverse, with universities differing in size, structure, culture and mission. Operating within constantly shifting economic contexts and policy environments, their success is essentially multi-dimensional - spanning research, teaching, enterprise, civic engagement and internationalisation. Leadership needs to take account of these complex contextual factors and be constantly adaptive to them. Inevitably, developments emerging on strategic agendas tend to be those that either have strong external drivers and/or enhance performance and impact across a range of core business areas. Responding to complexity also points towards adaptive leadership, recognising that challenges "can only be addressed through changes in people's priorities, beliefs, 
Pre-Print Version, accepted for publication in Health Education;

https://www.emerald.com/insight/content/doi/10.1108/HE-12-2020-0121/full/html

[subject to proofing]

habits and loyalties" (Heifetz et al., 2009:19) and that to ensure these changes are sustainable, a dialogic and shared approach is required (Fredricks et al., 2020; Bolden et al., 2015).

Secondly, effective leadership is inevitably influenced by both the personal qualities and values of individual leaders and the collective values of leadership teams: "by word, action, and example, values-based leaders seek to inspire and motivate, using their influence to pursue what matters most" (Jansen Kraemer Jr, 2011:2). In examining this, it is important to distinguish, and achieve balance, between doing and being. 'Doing', or leadership as praxis, is concerned with what the leader does and what they prioritise. Reflecting on what life is like for a senior leader - fast-paced, priority-driven, mission-focused and highly accountable - it becomes clear that cogent and persuasive reasons are needed for a new or emerging initiative to gain time, attention and commitment. 'Being', or ontological leadership, is a form of natural self-expression (Erhard et al., 2012) and concerns the congruence between values, actions and behaviours, and how this is modelled. Defined as "guiding others with the ultimate goal of improving their wellness" (Miller et al., 2005:4), altruistic leadership approaches, as they might be termed, align strongly with the values inherent in Health Promoting Universities, emphasising compassion, kindness, empathy, humility, emotional intelligence, authenticity and serving others. While leadership is often most visible through the characteristics of individuals, effective leadership can never rely on one person and requires commitment to sharing or distributing leadership. While, like many models, distributed leadership remains contested, it is generally understood to involve the sharing of influence by team members (Northouse, 2016: 365) with change agency flowing to points of need (Outram and Parkin, 2020), and the functions and processes of leadership being integrated across multiple roles, activities, relationships and systems (Bolden et al., 2009). Likewise, shared leadership, "a dynamic, interactive, influence process" (Pearce and Conger, 2002: 1), captures poignantly the challenge of empowerment that lies at the heart of a holistic, whole system approach.

Thirdly, effective leadership involves leveraging strategic engagement through working with decision triggers at an organisational level (Cialdini, 1984). Parkin (2013) proposes four approaches for engaging senior leadership support for specific initiatives: demonstrating links and consistency with the institutional mission, values and strategic goals; making a 'business case' based on contribution; illustrating sustainability in terms of meeting current and future needs; and showing how institutional quality will be enhanced. The importance of moving leadership engagement from notional support to active commitment is vital if health, wellbeing and sustainability are to become fully integrated into universities' strategic plans and aspirations. When successful, strategic leverage achieves what might be termed an organisational mind-shift, or a reappraisal of values, moving from 'we can't afford to...' to 'we can't afford not to...'.

\section{Aims and Methods}

This study critically explored leadership for the implementation of whole university approaches to health, wellbeing and sustainability, guided by the research questions: What are the characteristics of effective leadership for Health Promoting Universities and what are the opportunities to secure and sustain this? It was informed by theoretical perspectives such as salutogenesis, systems thinking and socio-ecology (Dooris et al., 2014) and catalysed by international developments (Okanagan International Charter for Health Promoting Universities and Colleges, 2015) and UK Healthy Universities Network members' concern about the challenges of securing senior-level leadership within a crowded higher education landscape.

As well as examining stakeholders' understandings of a whole university approach, as previously reported (Anonymised Reference, 2020), it examined vice-chancellors' and network members' perspectives on and experiences of leadership for Health Promoting Universities and examined the potential of the Okanagan Charter and other national and international frameworks to catalyse 
Pre-Print Version, accepted for publication in Health Education;

https://www.emerald.com/insight/content/doi/10.1108/HE-12-2020-0121/full/html

[subject to proofing]

whole university leadership and change. To ensure maximum utility, findings were used to formulate a guide for developing and securing effective leadership for Health Promoting Universities.

The study used a multi-method qualitative approach to examine stakeholders' experiences, perspectives and understandings within the context of their organisations (Denzin and Lincoln, 2008) and ethical approval was obtained from the two collaborating universities. Twelve vice-chancellors and ten Health Promoting University Co-ordinators from a total of 19 UK universities participated in the data collection, alongside ten Health Promoting University co-ordinators and six network coordinators from overseas. Within the UK, focus groups and semi-structured interviews were conducted jointly by one male and one female researcher, and were used to reveal both individual perceptions and perspectives shaped by interaction (Wilkinson, 2011). Outside of the UK, the study used online questionnaires - comprising both 'closed' (yes/no) and open (free text) questions - to access views from a geographically disparate sample (Wright, 2005), supplemented by two semistructured telephone interviews, conducted. The questionnaires, focus group schedules and interview questions all explored perspectives on Health Promoting Universities, leadership and the role of the Okanagan Charter. Data collection details are summarised below:

- 1 focus group with 8 participants, all members of the UK Healthy Universities Network facilitated by the two lead researchers (one male, one female)

- 1 focus group with 10 vice-chancellors from UK universities - facilitated by the two lead researchers (one male, one female)

- 2 individual interviews with vice-chancellors from UK universities - one conducted by each of the two lead researchers

- 5 individual interviews with Health Promoting University co-ordinators, 3 from the UK (1 of whom was also in the focus group), 1 from Australia, 1 from Canada - each conducted by one of the two lead researchers

- Questionnaire completed by 10 Health Promoting University co-ordinators from Australia/New Zealand, South America and North America

- Questionnaire completed by 6 Health Promoting University network co-ordinators from Australia/New Zealand, South America and North America

Data generated by the focus groups and interviews were recorded and transcribed verbatim. Along with data from the questionnaires, these were subjected to two stages of thematic analysis (Braun and Clarke, 2006). Firstly, inductive analysis - 'coding up' key themes emerging from the data by the secondary researcher. This was followed by deductive analysis - 'coding down' by the lead researchers, and cross-checking and further refinement to ensure that the final themes reflected the study's overarching research questions (Bowling, 2002; Hyde, 2008).

\section{Findings}

With regard to this paper's focus on leadership for Health Promoting Universities, the research data are presented using two of the three overarching themes used to develop the guide shown in Figure 1 - the third, 'Implementing a Whole University and Whole System Approach', being the focus of an earlier publication (Anonymised Reference, 2020):

- Characteristics of effective senior-level leadership

- Opportunities to secure and sustain effective senior-level leadership.

These are illustrated with quotes from the focus group and interviews with Health Promoting University coordinators (HU\#FG; HU\#IntX), the focus group and interviews with vice-chancellors (VC\#FG; VC\#IntX) and questionnaires completed by non-UK networks and their members (NW\#QuX; HU\#QuX). 
Pre-Print Version, accepted for publication in Health Education;

https://www.emerald.com/insight/content/doi/10.1108/HE-12-2020-0121/full/html

[subject to proofing]

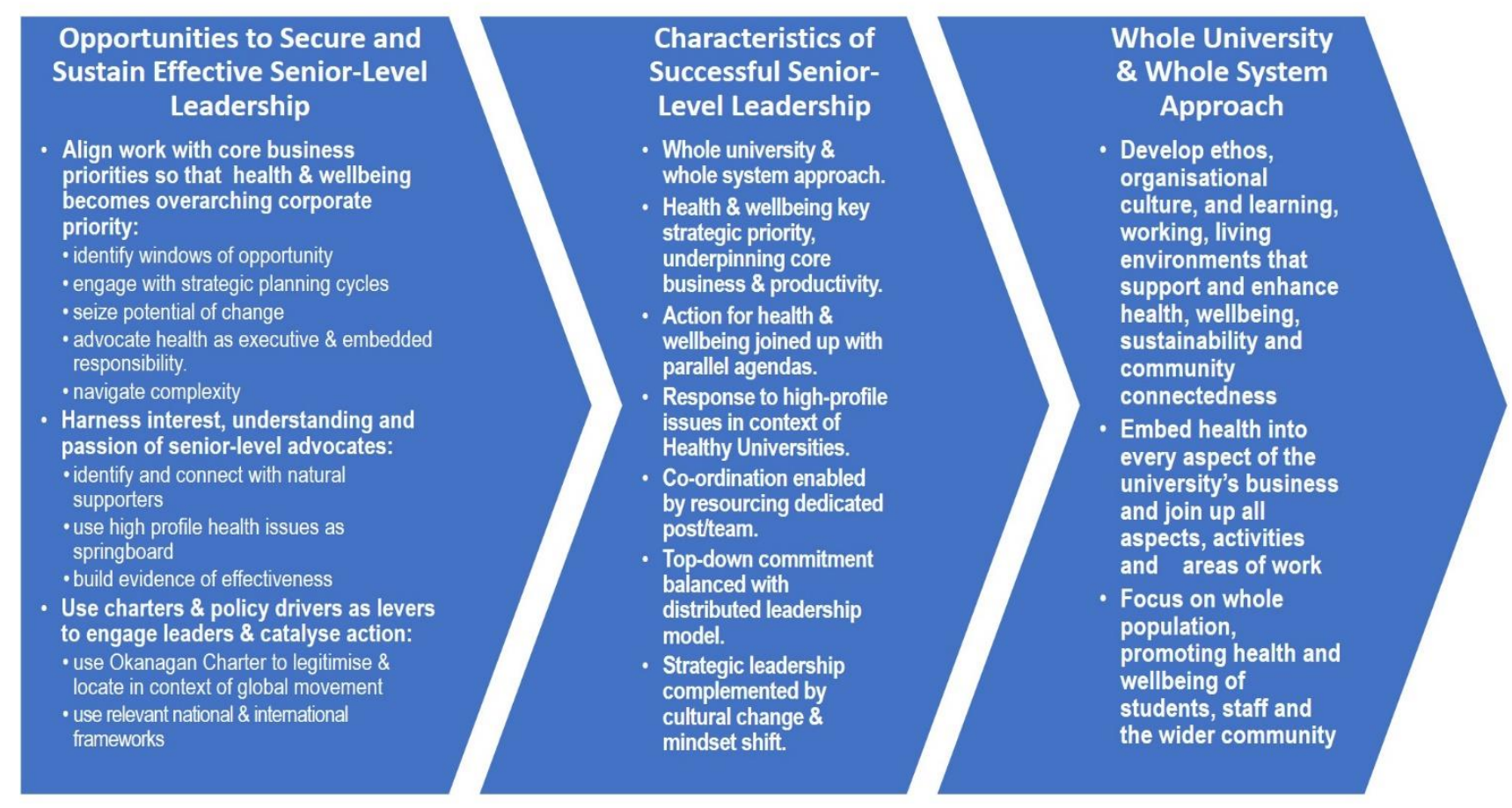

Figure 1: Developing and Securing Effective Leadership for Health Promoting Universities

\section{Characteristics of successful senior-level leadership}

Vice-chancellors and those involved in national networks identified a range of key features of successful leadership. Effective leaders were seen to have qualities linked to commitment and understanding, such that they could meaningfully articulate and advocate for Health Promoting Universities as involving whole university and whole system approaches at senior executive level:

"In terms of whole university leadership, there are some qualities to that you need to think about. There's something about the sort of people that are doing that leading. And it's not about personality - it's about the character, the engagement, the emotional intelligence of those people, and their commitment to a health and wellbeing agenda and their understanding of it." (HU\#Int1)

Successful leadership was seen by many to involve integrating explicit commitment to health and wellbeing within corporate strategy, evidenced by some universities 'naming' health as a high-level institutional priority and/or successfully incorporating their Health Promoting University commitment as a central driver within overarching documents guiding future planning and direction. Notably, these were institutions that had well-established initiatives and embraced a whole university approach:

"I kicked [the Healthy University] off as a strategic initiative in 2006/7... [and Health] will be one of the key themes that goes all the way through the University's 2030 strategy." (VC\#FG)

"We've now got to the level of buy-in where it looks like wellbeing will be part of our core University Strategy, one of the five big priority areas. So that's a kind of remarkable evolution. It had always been mentioned here and there in other strategic plans, but having something that's visible at that level...it's really influencing the whole University." (HU\#Int4)

Implicit in this approach was an understanding that Health Promoting Universities embrace, but go beyond, effective service provision - and a belief that health and wellbeing underpin the core 
Pre-Print Version, accepted for publication in Health Education;

https://www.emerald.com/insight/content/doi/10.1108/HE-12-2020-0121/full/html

[subject to proofing]

business of higher education, enhancing its productivity. This highlights the centrality of leadership for health and wellbeing connecting to key criteria such as student and staff experience, retention and performance, and of 'joining-up' with parallel agendas such as sustainability, equality, diversity and resilience. Linked to this, respondents from networks emphasised the importance of leaders responding to high profile issues such as mental health proactively and within the context of the whole system Health Promoting Universities framework. This emphasis flowed from concern that senior-level leaders tend to respond to such high-profile agendas reactively - and do not always appreciate connections to the broader Health Promoting Universities vision and can inadvertently undermine valuable whole institution work:

"I think the difficulty or the challenge would be, whilst our senior, very senior levels of staff see [mental health] as a priority, the challenge is not seeing it as part of a Healthy University idea." (HU\#FG)

Complementing strategic visibility, respondents highlighted investment in dedicated posts as another feature of senior-level commitment to enabling meaningful co-ordination and facilitating progress:

"The Pro Vice-Chancellor...supported the creation of a new, ongoing position in the University responsible for developing a University-wide Wellbeing Strategy and Action Plan...using population-based approaches and based on a holistic view of health and wellbeing." (HU\#Qu7)

Good leadership was also understood to involve balancing senior-level advocacy and commitment with a more 'distributed' approach, involving wide-ranging engagement and participation. This was seen to be pivotal to success, securing ownership of multiple stakeholders and adding authenticity and credibility to the leadership process. At one university, this was implemented through consciously integrating health across the institution rather than focusing attention on a centralised team:

"A cross-unit, embedded model for staff has been an effective way of creating distributed leadership and breaking down silos...more than a dozen staff have health promotion or wellbeing as a prominent part of their job title or job description in six different units and across two campuses... This mix of perspectives, expertise and reporting builds resilience and buy-in." (HU\#Qu9)

As part this approach, respondents emphasised the importance of senior-level leaders empowering those in the university community, linked to enhanced wellbeing:

"I think the more empowered you are, the more control you have over what you do - and there is an evidence base behind this - the healthier people are...and it is motivating and beneficial." (VC\#Int1)

One vice-chancellor cautioned about over-reliance on 'champions', who may lose energy and burnout. However, they also highlighted that good high-level leadership must draw on and be informed by motivated individuals able to advocate for health, sustainability and whole university change:

"You need 'thorns in your side', you need people who repetitively say the same thing until it becomes common practice.... wellbeing, Healthy University, environment, cycle paths, green areas... what do we mean by mental health? You need that constancy and repetition." (VC\#Int2)

While recognising the value of leaders formalising strategic commitment to health, vice-chancellors also emphasised the need to facilitate cultural change. Examples given included broadened committee remits - for example, from 'Health and Safety' to 'Health, Safety and Wellbeing' - and a wider shift of mindsets: 
Pre-Print Version, accepted for publication in Health Education;

https://www.emerald.com/insight/content/doi/10.1108/HE-12-2020-0121/full/html

[subject to proofing]

"I'm more interested, perhaps, in the overall culture and the ethos of an organisation than I am in systems and structures... that concept of, you know, collective responsibility for people's health and wellbeing, of people feeling open and free, whereby they can share their concerns...ensuring from my side that is properly resourced, that there's a no blame culture." (VCHFG)

Concerned to achieve such cultural change within the whole institution, one vice-chancellor had used his leadership to embed a set of underpinning values and encourage a shift from instrumental to compassionate and relational management, expressing a belief that effective engagement and transformation requires moving beyond mechanistic models of change. Similarly, another raised the question of how leadership for Health Promoting Universities can be holistic and help bring people together and provide a common sense of purpose:

"What part does the [Healthy Universities] agenda have to play in creating a sense of one University, single University, rather than silos and boundaries?" (VC\#Int1)

\section{Opportunities to secure and sustain effective senior-level leadership}

With regard to the process of securing and sustaining effective senior-level leadership for Health Promoting Universities, a number of opportunities and influencing factors were identified, which could be grouped under three organising themes.

The first concerned the importance of aligning Health Promoting Universities work with core business priorities so that health and wellbeing becomes a corporate priority, underpinning and supporting other strategic goals:

"Linking the benefits of wellbeing and health-promotion to the institution's strategic goals. For instance, showing research and evidence that resources spent on wellbeing initiatives pay big dividends in terms of student retention, and staff productivity." (HU\#Qu3)

Respondents acknowledged that moving health and wellbeing higher up the list of long-term strategic priorities, so that it becomes aligned with and is seen to underpin core business, can be extremely challenging:

"You need to have a number of...leaders willing to buy into the principles for health and wellbeing and not just look at the short-term financial investment. You also need to make sure that it is elevated to a top 3-5 priority..." (HU\#Qu9)

One means of overcoming this challenge was finding appropriate windows of opportunity and using these as entry points to catalyse conversations and put Health Promoting Universities on the agenda of senior leaders - where appropriate forging connections between agendas:

"[Healthy Universities] is place-based, every context is different and every community is different. You have to go where the momentum and the strengths and the energy are. But if you're intent on having conversations and reaching out to people who are supportive...I find that you can pick up steam and bring people in from some surprising corners." (HU\#Int4)

Strongly linked to this, engagement with universities' planning cycles was understood to be key, with respondents highlighting the importance of finding opportunities to integrate the Health Promoting University perspective within corporate strategy:

"We've already been asked by our vice-chancellor to think through how the Healthy University could be embedded within our 2020-2025 University Strategy. It's an amazing opportunity and challenge!" (HU\#FG) 
Pre-Print Version, accepted for publication in Health Education;

https://www.emerald.com/insight/content/doi/10.1108/HE-12-2020-0121/full/html

[subject to proofing]

Whereas organisational change was viewed negatively by some - with re-configurations and seniorlevel staff turnover representing barriers to progressing Health Promoting Universities and requiring 'yet another' awareness-raising process - others were more enthusiastic, emphasising opportunities offered by restructuring and the need to seize the potential offered by transitions. There was also recognition that success in elevating Health Promoting Universities, so that it is viewed as strategically important to mainstream business, requires a 'push' for health and wellbeing to be both 'named' as a senior executive-level responsibility and embedded within multiple roles.

"We've recently had some shift in our Vice-Chancellor's Executive Group, with some new senior people. Now one of those is going to be a Pro Vice-Chancellor, who's going to have a specific responsibility within their portfolio...[for] sport and corporate health and wellbeing." (HU\#Int2)

"It does need to be a distributed leadership, but somebody needs to pull it together, otherwise it's a fragmented leadership." (VC\#Int1)

Alongside this, it was widely acknowledged that universities are large and complex organisations and that navigating this complexity must be a priority if Health Promoting Universities work is to be successfully aligned with core business priorities. This highlighted the value of cross-university structures and ways of working:

"Because [the University's] structure is siloed, it actually prohibits people from going outside their service, from making partnerships...So they're very reliant on the Healthy University Group to be that place where they make the links. So that's why a Healthy University Group, having that oversight and having that reach across the whole University, that's why it's important." (HU\#Int1)

The second organising theme concerned harnessing the interest, understanding and passion of senior-level advocates, with both network members and vice-chancellors citing the professional background of high-level leaders as a key driver:

"So it's a personal interest, because my background's health, and public health in particular was the way in which I was coming in at it... What could I do that was different from what any other Vice-Chancellor? So it was a bit of 'this is my platform, this is my flag'. And at the time, the University needed a bit of healing and not too much bruising." (VC\#FG)

"It's partly about the Vice-Chancellor and his background [in health] and understanding, which has helped a lot. Without our current VC as our champion...[the Healthy University] wouldn't have been embedded as part of the University Strategy." (HU\#Int1)

Closely linked to this, the value of identifying and connecting with natural allies and supporters was highlighted, pointing to the need to invest time in networking and forging relationships across the institution. However, people commented that the wide-ranging focus of Health Promoting Universities made it challenging to know who was best-placed to be the lead champion or sponsor:

"Just by the nature of the work we do, it doesn't easily fit with one [senior leadership role]...it's how you choose and that can shift... because the work is so wide ranging that you can literally sit there and go, 'actually, I would argue, it almost fits with everybody'. That makes things very difficult to manage!" (HU\#FG)

Respondents pointed to the value of using high-profile agendas to lever senior-level engagement in Health Promoting Universities. They were overwhelmingly positive about the prominence given to particular health challenges, notably student mental health via Universities UK's Stepchange Framework (Universities UK, 2020). However, while recognising these as important entry points, 
Pre-Print Version, accepted for publication in Health Education;

https://www.emerald.com/insight/content/doi/10.1108/HE-12-2020-0121/full/html

[subject to proofing]

they had also experienced challenges - expressing concern about a lack of co-ordination and integration:

"I think there is buy-in, in terms of addressing current agendas and policy that's coming in to direct the University, for example, mental health... [but] I don't think it's anything to do with recognising the ideology of a Healthy University." (HU\#FG)

"A number of networks have recently been established (e.g. substance use, best practices in mental health). If efforts are not coordinated, there is potential for all network activities to be weakened. (NW\#Qu4)

More widely, there was consensus that persuasive evidence of effectiveness is important as a driver for harnessing the commitment of senior-level leaders to prioritise Health Promoting Universities, through using evaluation to make the case for investing in health and wellbeing alongside sustainability, diversity and inclusion and, where appropriate, indigenous engagement. However, while Network members held a strong belief that key indicators such as retention and achievement are influenced by health and wellbeing, they also emphasised the challenge of measuring this quantitatively and thereby gaining leaders' buy-in. Vice-chancellors highlighted the importance of an evidence base to move the Health Promoting University beyond the stage of strategic commitment and guide action that will deliver better outcomes for students and staff:

"The difficulty is knowing what to do actually. It's not recognising the importance of the issue, it's knowing how to gain traction with it...And it comes back to...tying it in to the objectives of the University in an evidential way, so it's very clear that this is what we ought to be doing, rather than just a sense of 'it feels like the right thing to do'." (VC\#Int1)

A particular challenge was to go beyond evaluating the delivery of specific services to capture the added value of a whole university approach in both quantitative and qualitative terms:

"We haven't ever had the capacity to measure the whole impact. I don't know if anybody has, I think it's just one of the difficult areas to do. And even how we would do that..." (HU\#Int3)

The third organising theme concerned the use of external charters and policy drivers to engage leaders and catalyse action. A wide-reaching focus was the Okanagan International Charter for Health Promoting Universities and Colleges, which was understood to be not only inspirational, but also extremely valuable as a mechanism to legitimise Health Promoting Universities work and locate this in the context of a global movement:

"It has a strong and compelling vision. It has a global scope." (HU\#Qu3)

"We've used it to try to persuade at a very senior level... that there is an international structure with a very clear framework of how your organisation can become a Healthy University, and the steps that you need to take to do that." (HU\#FG)

While not necessarily utilising it as an overarching guiding framework, those involved in networks highlighted strong resonance with its principles and content, particularly the two calls to action embedding health in all aspects of campus culture and leading health promotion action and collaboration locally. There was, though, some caution about the Charter's overall utility, with respondents highlighting the need to close the 'implementation gap' through translating high-level commitments into practical culturally and contextually appropriate actions:

"The Okanagan Charter is a useful framework but local feedback suggests that a gap exists about more practical steps and staging for achieving the calls to action." (NW\#Qu1) 
Pre-Print Version, accepted for publication in Health Education;

https://www.emerald.com/insight/content/doi/10.1108/HE-12-2020-0121/full/html

[subject to proofing]

"I think the challenge... is getting buy-in to implement it because the question from a lot of senior people is 'this is a really nice document but how do I actually go about implementing it?'...So I think it's challenging for them to apply it in their own institution." (HU\#Qu5)

While one respondent suggested that the Charter could be used to develop an international 'rating' scheme, many others focused on the challenge of engaging their leaders, pointing to the need to increase awareness and understanding and persuade them of the tangible benefits of engaging with and implementing the Charter. This challenge was illustrated by UK vice-chancellors, who were largely unaware of the Charter or viewed it as just one of many documents that contribute ideas and feed into decision-making processes. They also expressed some concern about its status in terms of its seeming lack of 'ownership' by any one international body, and its language:

"I'm sure any framework that brings things together like this is helpful...It's great, lovely, but who owns this?...I've got lots of frameworks I have to implement as well. So how can I mesh it together with what I've already got institutionally, and to best effect, and where can I look to connect with good practice that I might use?" (VC\#FG)

Most national networks had built commitment to the Okanagan Charter into their membership structure, linked to an opportunity or requirement for vice-chancellors to act as signatories:

"We have also asked our members to present the Charter and ask senior leadership to 'sign on' to the principles of the Charter." (NW\#Qu3)

Within the UK, network members endorsed the Network's introduction of new membership criteria incorporating an explicit commitment to the Okanagan Charter and an option for senior-level executive sign-up, viewing this as an important signifier that in committing to adopting Health Promoting Universities, an HEl is part of a global movement:

"It's not just someone whose thought up of an idea, it's actually part of a bigger movement... having [the Okanagan Charter] as part of [the Network's membership process] is definitely beneficial because it brings awareness...it's not just a little project that someone's doing." (HU\#FG)

In addition to discussing the Okanagan Charter, vice-chancellors and network members made connections to relevant external strategies and frameworks as potentially useful drivers in securing leadership and action. At an international level, these included the United Nation's Sustainable Development Goals, with which the Okanagan Charter was seen to be closely aligned:

[The Okanagan Charter] is a useful catalyst for the development of the initiative of health promoting Universities, bearing in mind that we are immersed in meeting the Sustainable Development Goals, so it is necessary to meet them to have healthy populations." (NW\#Qu6)

Within the UK, alongside mention of workplace health charters, the Wellbeing of Future Generations Act (Wales) was highlighted. This likewise aligns closely with the Okanagan Charter's focus on health and sustainability and the wellbeing of people, place and planet:

"In Wales, with sustainable development being embedded within the constitution and the Wellbeing of Future Generations Act being enacted, that's been our focus, as it were, in ensuring that our Healthy University Strategy aligns to that...Actually, the principles are the same as the Okanagan Charter...It's something that we refer to but it's not the driver for what we're doing." (HU\#Int2)

\section{Discussion}


Pre-Print Version, accepted for publication in Health Education;

https://www.emerald.com/insight/content/doi/10.1108/HE-12-2020-0121/full/html

[subject to proofing]

This research explored the views of both UK vice-chancellors and those involved in UK and non-UK Health Promoting Universities networks, with a view to producing recommendations, a set of illustrative institutional case studies and a guide to securing and sustaining effective senior-level leadership for Health Promoting Universities. The scope of the study was limited - in part due to resource constraints restricting the amount of data collection, in part due to the challenges involved in accessing and engaging vice-chancellors, and in part due to the lack of established networks in Africa and Asia at the time the research was conducted. However, the study generated a wealth of informative data and the analysis revealed valuable perspectives relating to leadership for Health Promoting Universities.

As Figure 1 shows, members of Health Promoting Universities networks identified multiple influencing factors and opportunities to secure, sustain and strengthen senior-level leadership. With reference to aligning work with core business so that health and wellbeing becomes a strategic priority (Parkin, 2013), these included: finding appropriate entry points and windows of opportunity for agenda-setting; engaging with strategic planning cycles; utilising the potential offered by organisational change; advocating for health to be both named as a responsibility within a senior leader's role and embedded in multiple roles across the university; and learning to navigate the large-scale and complex nature of universities. In relation to harnessing the personal qualities and values of senior-level advocates (Jansen Kraemer Jr, 2011) - their interest, understanding and passion - the following sub-themes emerged: identifying and engaging with your natural allies; using high-profile concerns as catalysts and levers; and generating a persuasive evidence base. With regard to using charters and policy drivers as levers to engage and catalyse action, attention focused on both the Okanagan Charter for Health Promoting Universities and Colleges (2015) and other international and national frameworks such as the Sustainable Development Goals (United Nations, 2015) and Wellbeing of Future Generations Act (Wales) (2015). In discussing the Okanagan Charter, members of both UK and other national networks highlighted its inspirational nature and the significance of its international status in engaging senior-level buy-in. Although many Health Promoting University initiatives were not using it as an overarching framework, its principles and calls to action were widely valued - although the challenge of moving from commitment to effective implementation was also emphasised. While some universities outside of the UK had secured highlevel adoption of the Charter or discussed how the Charter could be used as an international rankings-related driver, UK vice-chancellors were largely unaware of it or viewed it as just one of many external documents to draw upon. However, most national networks had built commitment to the Okanagan Charter into their membership structure, linked to an opportunity or requirement for vice-chancellors to act as signatories - an approach broadly welcomed in the UK.

Effective, authentic and credible senior-level leadership was understood to be a pre-requisite for the successful implementation of a Health Promoting University initiative. As illustrated in Figure 1, such leadership was seen to involve commitment to whole university/whole system working, as explored by Anonymised Reference (2020), coupled with an understanding that health and wellbeing underpins core university business and must therefore be a properly resourced strategic priority. The importance of knitting together agendas in a positive way is seen as key to this, with effective leadership involving a recognition that more can be achieved by connecting health with parallel agendas such as sustainability, resilience, equality and diversity - and by taking a proactive, integrated and even sometimes 'opportunistic' approach to high-profile concerns such as student mental wellbeing. The processes involved - of connecting, aligning and finding windows of opportunity to achieve influence and strategic leverage through incorporating health, wellbeing and sustainability into high-level organisational planning cycles - are all ultimately about emphasising and making the case for interdependence. This in turn spotlights the necessity of collaborative leadership (Archer and Cameron, 2013), which is premised on the belief that when people are brought together with access to high-quality information, they are able to work together 
Pre-Print Version, accepted for publication in Health Education;

https://www.emerald.com/insight/content/doi/10.1108/HE-12-2020-0121/full/html

[subject to proofing]

authentically to generate the vision and strategies necessary to tackle shared concerns (Chrislip and Carl, 1994). Alongside this, the data emphasised a commitment to wrestling with the challenges of implementing shared and distributed leadership (Pearce and Conger, 2002; Bolden et al., 2009), in ways that secure widespread ownership and empowerment. As one of the respondents observed, distributed leadership must not mean fragmented leadership, and there is an artful balance to be struck between central coordination and oversight with devolved approaches that look to foster collective engagement at multiple levels.

These findings, and the support for collaborative and distributed approaches, relate strongly to boundary-spanning leadership. This highlights the value of breaking out of silos and appreciates that boundaries tend to be places where innovation and new types of collaboration emerge. Defined as "the capability to establish direction, alignment, and commitment across boundaries in service of a higher vision or goal" (Yip et al., 2011: 4), this approach is based on three priorities: collaboration across functions; empowerment of employees at all levels; and cross-organisational learning. From this perspective, it is noteworthy that traditional notions of leader influence linked to positional authority and structural hierarchies are of limited effectiveness for agendas that do not provide a direct 'easy-to-measure' organisational return, and which call for boundary-spanning collaboration (ibid.). A dual operating system has been proposed (Kotter, 2014) which addresses the limitations of hierarchies by setting alongside them an emphasis on dynamic, energetic, adaptive networking systems. These free-up the hierarchy by empowering individuals to create and participate in spheres of influence that work across siloed lines of reporting to achieve impact in a more immediate and flexible way: "the new system adds needed agility and speed while the old one, which keeps running, provides reliability and efficiency" (ibid.: viii). This approach has been advocated for the parallel agenda of environmental sustainability, using what has been termed the 'Core Business Integration of Sustainability' (Sharp, 2015). To generate the energy and interest needed for a networked sphere of influence to have impact, an appreciative approach to change (Lewis et al., 2015) is important - identifying, celebrating and building positively upon good practices already in place.

As well as resonating with altruistic leadership approaches (Miller et al., 2005), which, as discussed in the Introduction, align with the values base of Health Promoting Universities, the findings emphasised that effective leadership must combine high-level commitment and strategic intent with transformational change linked to cultural investment. Strategic intent brings together three considerations. First, a profound understanding of organisational purpose, the definition of which, according to Bartlett and Ghoshal (1994), must be the first responsibility of senior management. Second, and informed by this clarity of purpose, a focus on the future and the hard work of 'choice' involved in developing and implementing the strategy needed to get there (Rumelt, 2012). Third, an articulation of the values that drive how organisational communities live and work together. Lencioni (2002) distinguishes between core values - embedded principles guiding action and serving as cultural cornerstones; and aspirational values, which an organisation needs to succeed but currently lacks. The Health Promoting University offers significant potential to bridge between core and aspirational values, bringing key agendas such as student mental health and climate emergency commitments into the central dialogue of organisational strategy. More generally, to become genuinely and sustainably integrated within an institution's strategy, the Health Promoting University must resonate with all three aspects of strategic intent. This points to another aspect of strategic leadership - sense-making and finding meaning through dialogue, social exchange and collaborative engagement (Drath and Palus, 1994). This focus is about the leader's ability to find connections and navigate the complexity of competing policy agendas. As informed and influential practitioners, Health Promoting University co-ordinators can assist in this process, presenting a coherent way forward which is strategically valuable to those in decision making roles. 
Pre-Print Version, accepted for publication in Health Education;

https://www.emerald.com/insight/content/doi/10.1108/HE-12-2020-0121/full/html

[subject to proofing]

Linking closely with organisational values, cultural investment highlights questions of individual and collective influence. As Figure 1 illustrates, whole university and whole system approaches involve developing the ethos and organisational culture of the institution, and this needs to be done in ways that connect not only with organisational purpose, but also with place - focusing on civic engagement with the wider community in which the institution operates and resides. Sometimes referred to as 'the forgotten half of change' (De Brabandere, 2005), transforming organisational culture and cultural perceptions is the true essence of sustainable strategic change. Behind this lies a powerful congruence between an organisation's espoused values and the lived experience of the institutional community: "successful organisations tend to be those which possess assumptions and values which encourage behaviours consonant with the organisational strategy" (Hassard and Sharifi, 1989, as adapted and cited in Brown, 1998:163). This is likely to require moving to more relational approaches to leadership, developing collective commitment through collaborative and transparent processes. As Parkin (2017: 114) observes, "it is important for leaders to be aware that there is a clear relationship between engagement, commitment and accountability."

\section{Conclusion}

This international research study engaged with multiple stakeholders to examine leadership for health, wellbeing and sustainability within the higher education sector. As reported above, key opportunities for securing effective leadership included: alignment with core business such that the health is understood to underpin corporate priorities and strategic intent; harnessing the passion and drive of allies and champions; and using charters and policy drivers to engage and lever action. Key characteristics of such leadership included: adoption and resourcing of a whole university/whole system approach; combining strategic direction with cultural investment for change; joining-up across agendas and boundaries; and balancing top-down commitment with distributed/shared approaches. As discussed above, the findings resonated with a number of approaches, including altruistic, collaborative and boundary-spanning leadership - reflecting values inherent in Health Promoting Universities.

At the time of writing, universities worldwide have been impacted profoundly by COVID-19. The pandemic has been hugely disruptive but also offers potential to be transformative. Reflecting on the disruption within higher education, Blonkers (2020) suggests that, beyond phases focused on immediate response and short-term recovery, we need to re-imagine the business of higher education in the post-pandemic world. As universities plan ahead, there are a range of concerns to take into account and balance: using space and place in ways that preserve social distancing whilst enabling academic and non-curricular interaction (Parkin and Brown, 2020); offering blended learning that preserves a high quality student experience; reconfiguring student accommodation options; enabling a sense of belonging and community within the 'new normal' of life on- and offcampus; anticipating and responding to the long-term mental health impacts of COVID-19; and prioritising actual and perceived safety alongside the wider health and wellbeing of students and staff and the civic role of the university in its community. Alongside these considerations, prompted largely by the threats arising from COVID-19, there is a wider discourse about the opportunities that the pandemic has opened up. In planning for longer-term recovery, there is clearly potential for transformational change: do we go back to the 'old normal' or do we imagine a and commit to a new and different future? The disruption caused by COVID-19 has provided glimpses of what is possible both within and outside of higher education. For example, universities worldwide have experienced vastly reduced energy use on campus through the reduced use of buildings and other facilities; a marked decrease in commuting and business travel, with health and sustainability benefits; and a realisation that learning, teaching and other forms of university business can, at least to some extent, take place effectively using online communication platforms. While the pandemic has shone 
Pre-Print Version, accepted for publication in Health Education;

https://www.emerald.com/insight/content/doi/10.1108/HE-12-2020-0121/full/html

[subject to proofing]

a spotlight on societal and global injustice and inequalities, there have been powerful insights into what a healthier and more sustainable future could look like: reduced air pollution and carbon emissions; increased uptake of cycling and walking as forms of both commuting and leisure travel; re-evaluation of life/work balance; and discovery of the benefits of a fundamental reconnection with nature.

All of this points to the opportunity for higher education to use the disruptive impact of COVID-19 as a catalyst to 'build back better' - harnessing its leadership to effect visionary change both within universities and in society as a whole. This task will require leadership that values wellbeing, prioritises whole university/whole system approaches and combines inspirational, transformative, collaborative and boundary-spanning perspectives. In this regard, the Okanagan Charter for Health Promoting Universities and Colleges (2015) captures the enormity of this ambition - calling on HEls not only to incorporate health and sustainability into their mission and strategic plans, but also to lead and drive transformative change in current and future societies, thereby contributing to the wellbeing of people, places and the planet.

\section{Notes}

[1] The term 'higher education' is used generally to refer to post-secondary education. The Okanagan Charter for Health Promoting Universities and Colleges (2015) takes as its remit universities, colleges and other organisations that make up the post-secondary sector. However, it is important to note that different countries have different education systems: in the UK, for example, 'further education' refers to study after secondary education that is not taken as part of an undergraduate or postgraduate degree. For the purposes of this study, participants were recruited primarily via existing networks, respecting their varying inclusion criteria.

[2] The terms 'health promoting university', 'healthy university' and 'healthy campus' tend to be used in different countries and contexts to mean much the same thing, even though it can be argued that there are semantic differences between them (e.g. Dooris, 2006), the reality is that they have often been used interchangeably, For the purposes of consistency, 'health promoting university' is used throughout this paper except in relation to the UK Healthy Universities Network and when other terms are used in quotations.

\section{References}

Archer, D. and Cameron, A. (2013). Collaborative Leadership: Building Relationships, Handling Conflict and Sharing Control, 2nd edn. London: Routledge.

Bartlett, C. A. and Ghoshal, S. (1994). Beyond Strategy to Purpose. Harvard Business Review, November - December.

Bolden, R., Petrov, A. and Gosling, J. (2009) Distributed Leadership in Higher Education: Rhetoric and Reality. Educational Management Administration and Leadership, 37 (2): 257-277.

Bolden, R., Jones, S., Davis, H. and Gentle, P. (2015) Developing and Sustaining Shared Leadership in Higher Education. London: Leadership Foundation for Higher Education (now Advance HE).

Bowling, A. (2002) Research Methods in Health: Investigating Health and Health Services, $2^{\text {nd }}$ edn. Buckingham: Open University Press. 
Pre-Print Version, accepted for publication in Health Education;

https://www.emerald.com/insight/content/doi/10.1108/HE-12-2020-0121/full/html

[subject to proofing]

Braun, V. and Clarke, V. (2006) Using thematic analysis in psychology. Qualitative Research in Psychology 3(2): 77-101.

Brown, A. (1998). Organisational Culture, (2nd ed.). Harlow, UK: Pearson Education Limited.

Bryman, A. (2007). Effective Leadership in Higher Education: An Analysis of the Research Literature from Various Sectors. London: Leadership Foundation for Higher Education (now Advance HE).

Cialdini, R. (1984). Influence: The Psychology of Persuasion (also published as the textbook Influence: Science and Practice). New York: Harper Collins.

De Brabandere, L. (2005). The forgotten half of change: achieving greater creativity through changes in perception. Chicago, IL: Dearborn trade publishing.

Denzin, N. and Lincoln, Y. (2008) Introduction: The discipline and practice of qualitative research. In NK Denzin, YS Lincoln (eds.) Strategies of Qualitative Inquiry. London: SAGE, pp.139-164.

Dooris, M. (2006) Editorial - Healthy settings: future directions. Promotion and Education XIII(1): 4-6.

Dooris, M. (2013) Expert voices for change: bridging the silos - towards healthy and sustainable settings for the 21st century. Health and Place, 20, 39-50.

Dooris, M., Wills, J. and Newton, J. (2014) Theorising Healthy Settings: a critical discussion with reference to Healthy Universities. Scandinavian Journal of Public Health, 42, 7-16.

Dooris, M., Powell, S. and Farrier, A. (2020) Conceptualising the 'whole university' approach: an international qualitative study. Health Promotion International, 35(4), 730-740.

Drath, W. H. and Palus, C. J. (1994). Making Common Sense: Leadership as Meaning-Making in a Community of Practice. Greensboro, NC: Center for Creative Leadership.

Erhard, W. H., Jensen, M. C. and Granger, K. L. (2012). Creating Leaders: An Ontological/ Phenomenological Model. In Snook, S., Nohria, N. and Khurana, R. (eds), The Handbook for Teaching Leadership: Knowing, Doing, Being. Thousand Oaks, CA, London, and New Delhi: Sage Publications.

Ernst, C. and Chrobot-Mason, D. (2010). Boundary Spanning Leadership: Six Practices for Solving Problems, Driving Innovation, and Transforming Organizations. New York: McGraw-Hill Professional.

Ernst, C. and Yip, J. (2009) Boundary spanning leadership: Tactics to bridge social identity groups in organizations. In Pittinsky, T. L. (ed), Crossing the divide: Intergroup leadership in a world of difference (pp.89-99). Boston: Harvard Business School Press.

Fredricks, C., James, H. and Maclean, A. (2020). Architectural blueprint or work of art? Learning lessons from emergent change and the function of dialogic leadership. In Potter, J. and Devecchi, C. (eds.), Delivering Educational Change in Higher Education: A Transformative Approach for Leaders and Practitioners (SEDA Series). Oxon and New York: Routledge.

Goddard, J. (2009). Reinventing the civic university. NESTA. https://www.nesta.org.uk/report/reinventing-the-civic-university <accessed 18 December 2020>.

Hassard, J. and Sharifi, S. (1989). Corporate Culture and Strategic Change. Journal of General Management, 15 (2), 4-19.

Heifetz, R., Grashow, A. and Linsky, M. (2009). The Practice of Adaptive Leadership: Tools and Tactics for Changing your Organization and the World. Boston, MA: Harvard Business Review Press. 
Pre-Print Version, accepted for publication in Health Education;

https://www.emerald.com/insight/content/doi/10.1108/HE-12-2020-0121/full/html

[subject to proofing]

Hunter, D., Marks, L., Brown, J., Scalabrini, S., Salway, S., Vale, L., Gray, J. and Payne, N. (2016) The potential value of priority-setting methods in public health investment decisions: qualitative findings from three English local authorities. Critical Public Health, 26(5): 578-587.

Hyde, K. (2008) Independent Traveler Decision-making. In A. Woodside (ed.) Advances in Culture, Tourist and Hospitality Research, Volume 2. Bingley: Emerald Group, pp. 43-151.

Jansen Kraemer Jr, H. M. (2011). From Values to Action: The Four Principles of Values-Based Leadership. San Francisco, CA: Jossey-Bass.

Jones, S., Harvey, M., Hamilton, J., Bevacqua, J., Egea K. and McKenzie, J. (2017) Demonstrating the impact of a distributed leadership approach in higher education. Journal of Higher Education Policy and Management, 39(2): 197-211

Lencioni, P. (2002). Make Your Values Mean Something. Harvard Business Review, July.

Miller, L. M., Fink, J. S., Pastore, D. L. and Baker, R. E. (2005). Defining Altruistic Leadership in the Management of Intercollegiate Coaching. The SMART Journal, 2(1): 4-16.

Northouse, P. G. (2016). Leadership: Theory and Practice, $7^{\text {th }}$ edn. Thousand Oaks, CA, London, and New Delhi: Sage Publications.

Lewis, S., Passmore, J. and Cantore, S. (2015). Appreciative Inquiry for Change Management: Using Al to Facilitate Organizational Development. Philadelphia, PA, London, and New Delhi: Kogan Page.

Okanagan Charter for Health Promoting Universities and Colleges (2015) Okanagan Charter: An International Charter for Health Promoting Universities and Colleges. Kelowna, British Columbia, Canada. https://open.library.ubc.ca/cIRcle/collections/53926/items/1.0132754 <accessed 18 December 2020>.

Orme, J. and Dooris, M. (2010) Integrating health and sustainability: the higher education sector as a timely catalyst. Health Education Research 25(3): 425-437.

Outram, S. and Parkin, D, (2020). A tailored undertaking: the challenge of context and culture for developing transformational leadership and change agency. In Potter, J. and Devecchi, C. (eds), Delivering Educational Change in Higher Education: A Transformative Approach for Leaders and Practitioners (SEDA Series). Oxon and New York: Routledge.

Owen, L., Morgan, A., Fischer, A., Ellis, S., Hoy, A. and Kelly, M. (2012) The cost-effectiveness of public health interventions. Journal of Public Health, 34(1):37-45.

Parkin, D. (2013). Leading Transformation in Learning and Teaching, leadership development programme run by the Leadership Foundation for Higher Education, UK. Materials version, 3 July 2013. Advance HE: UK.

Parkin, D. (2017). Leading Learning and Teaching in Higher Education: The key guide to designing and delivering courses. Oxon and New York: Routledge.

Parkin, D. and Brown, G. (2020) Creating Socially Distanced Campuses and Education Project. Final Capstone Report. York: Advance-HE. https://www.advance-he.ac.uk/knowledge-hub/creatingsocially-distanced-campuses-and-education-project-final-capstone-report <accessed 18 December 2020>.

Patton, M. (1990) Qualitative Evaluation and Research Methods. 2nd edn. Newbury Park, CA: Sage.

Pearce, C. L. and Conger, J, A. (2002) Shared Leadership: Reframing the Hows and Whys of Leadership. Thousand Oaks, CA, London, and New Delhi: Sage Publications. 
Pre-Print Version, accepted for publication in Health Education;

https://www.emerald.com/insight/content/doi/10.1108/HE-12-2020-0121/full/html

[subject to proofing]

Rumelt, R. (2012). Good Strategy/Bad Strategy: The Difference and Why It Matters. London: Profile Books Ltd.

Sharp, L. (2015). Put simply, we are in the wrong organizational vehicle for the 21st century.

Available at https://www.usgbc.org/articles/put-simply-we-are-wrong-organizational-vehicle-21stcentury <accessed 18 December 2020]>.

Suárez-Reyes, M. and Van den Broucke, S. (2016) Implementing the Health Promoting University approach in culturally different contexts: a systematic review. Global Health Promotion 23 (Suppl. 1): 46-56.

Universities UK (2020) Stepchange: Mentally Healthy Universities. London: UUK. Available at https://www.universitiesuk.ac.uk/policy-and-analysis/reports/Documents/2020/uuk-stepchangemhu. pdf <accessed 18 December 2020>.

UPP Foundation Civic University Commission (2019). Truly civic. Strengthening the connection between universities and their places. London: UPP Foundation.

Wilkinson S. Analysing focus group data. In Silverman, D. (ed.) Qualitative Research, 3rd edn. London: SAGE, 2011, pp. 168-184.

World Health Organization (2014) The case for investing in public health: The strengthening public health services and capacity - a key pillar of the European regional health policy framework Health 2020. Copenhagen: WHO. http://www.euro.who.int/_data/assets/pdf_file/0009/278073/CaseInvesting-Public-Health.pdf?ua=1 <accessed 18 December 2020>.

Wright, K. (2005) Researching internet-based populations: advantages and disadvantages of online survey research, online questionnaire authoring software packages, and web survey services. Journal of Computer-Mediated Communication 10(3). http://onlinelibrary.wiley.com/doi/10.1111/j.10836101.2005.tb00259.x/full <accessed 18 December 2020>.

Yip, J., Ernst, C. and Campbell, M. (2011). Boundary Spanning Leadership: Mission Critical Perspectives from the Executive Suite (part of the Center for Creative Leadership Organizational Leadership White Paper Series). Greensboro, NC: Center for Creative Leadership. 